\title{
The Chinese sports economy and the professional construction
}

\section{management research}

\author{
Feng Sun \\ College of physical education, Shandong University of Finance And Economics, Jinan Shandong \\ 250014
}

\begin{abstract}
Key words: colleges and universities sports teaching practice teaching economics and management theory
\end{abstract}

\begin{abstract}
This research adopts literature, questionnaire, interview and case analysis research methods such as the nanjing sports college sports economics and management of professional theory and practice class teaching present situation has carried on the investigation and study, Basis for sports economic and management professional talent training target and teaching situation, respectively from theory and practice teaching content and link, students employment and the relevance of the specialty, students in the process of employment and professional practice, the application of the professional theory knowledge, the effect of practice courses, practice teaching base of the situation and students' satisfaction in the practice teaching base, etc to do the analysis and research,Points out the characteristic and deficiency existing in the teaching, to colleges and universities sports curriculum and develop the economic and management of provide some useful reference and reference.
\end{abstract}

\section{Introduction}

he sports industry in our country is a burgeoning industry, the enormous potential that broad prospects for 2008, the convening of the 2008 Olympic Games in Beijing is greatly encourage and stimulate the development of the sports industry of our country.As soon as in particular on September 3, 2014, the State Council about cancels the news which the commercial character and the mass sports sports event examine and approve to pass through publicly, is causes the vibration inside and outside the world of sport, the folk manages the match strength to run around spreading the news, thought the sports performed market the spring soon to arrive. For the time being, however, the development of the sports industry of China on the quality and efficiency of the least developed countries and there is still a relatively large gap due to the sports industry development in China is not a long time, sports and a serious shortage of professionals to carry out a variety of the efficient allocation of resources.Sports and sports-related areas in sports economic and management of application-oriented expertise of a serious lack of china sports industry of high-speed development of the great resistance.

In this case, some national sports colleges and universities have to offer or plan to open a sports economy and management.Nanjing sports school as the only professional sports colleges and universities in jiangsu province, in 2009 began to recruit professional sports industry management, together with Beijing sports university become typical of the sports industry and management schools, in 2013 changed its name to professional sports economy and management. Now we have two graduates, the study of the two graduate employment situation as well as the graduating class of 2015 undergraduate students is system of professional practice of investigation and study, aimed at 
nanjing sports college sports economics and management in the future of professional training, recruitment and employment provide strong reference and reference 。

\section{The research object}

The nanjing sports college sports economic and management specialty has started the theory and practice teaching, the students' employment and the role of professional practice as the specific research object, to analyze it.

\section{The research methods}

Through Chinese hownet, ten thousand party, d PuZhongWen founder electronic books and periodicals such as digital resources refer to a large number of domestic and international about the research achievements of teaching reform of institutions of higher learning, and professional sports economic and management data, analyze the nanjing sports college sports economics and management measures for the management of professional training scheme, internships, etc., laid a theoretical basis for the study 。

A. Questionnaire Survey Method

This research firstly according to the relevant factors of teaching design for Beijing sports college sports economic and management professional teaching circumstance of questionnaire.

The closed and semi-closed cross hybrid questionnaire.In March 2013 to nanjing sports college sports industry management level 2009, March 2014 to level 2010 sports economy and management majors, and in September 2014 to level 2011 sports economy and management majors in questionnaires, 101 questionnaires out of three grade, recovery of 93 copies, recovery rate was $92.1 \%$, of which 90 valid questionnaires, effective rate was $96.8 \%$.

B. Interview Survey Method

The study involved in the investigation of 2009 grade management professional sports industry and sports in grade 2010, 2011, the economy and management majors through class, telephone and network in the form of interview, in a more intuitive understanding of the understanding and the understanding of teaching from students. Questionnaire survey based on the start of formulation and test the reliability and validity.

C. Individual Cases Analysis

In order to shorten the process and broaden the research depth, the study of nanjing sports college sports economic and management theory and practice class is part of the teaching of case study separately, on the basis of general research supplemented by case studies.So can help sports effective development of economy and management, can provide a deep research for its teaching and research paradigm.

\section{Analysis and discussion}

Nanjing sports college sports in the economic and management professional training scheme of undergraduate course teaching, graduation should always learn is divided into 165 credits. Teaching link consists of two parts, the classroom teaching and practice teaching, the classroom teaching should be 148 credits, accounting for $89.7 \%$ of the total credit, practice teaching should be 17 credits, accounting for $10.3 \%$ of the total credit.According to the nanjing sports college sports economics and management professional training objectives: "to learn basic knowledge of the operation and management as the foundation, grasp the sports marketing, sports venues management theory and method, can be engaged in business management in fitness clubs, sports 
venues and sports events, sports product marketing planning, communication management, management, can understand sports and planning professionals." As you can see, put theory into practical application is the most prominent feature of this major, but, on the credits set, the study suggests that the proportion of practice teaching link slightly weak.

A. Classroom teaching link analysis

Nanjing sports college of economy and management professional undergraduate course teaching classroom teaching link consists of two parts, the compulsory courses and elective courses, credits for a total of 148 credits, accounting for $89.7 \%$ of the total credit; Compulsory course for a total period of 2664 hours, of which the total is divided into 94 , accounting for $56.9 \%$ of the graduation total credit, period number is 1692, accounting for $63.5 \%$ of the total class hours.Elective course learning is divided into total 54, accounting for $32.7 \%$ of the graduation total credit, period number is 972 , accounting for $36.4 \%$ of the total number of hours. In the compulsory course, consists of general education, the trunk of basic courses and professional core courses, credits, 33, 41 and 20 respectively, the total credits proportion is $24.8 \%, 20 \%$ and $12.1 \%$ respectively; Period of respectively 738, 594 and 738 hours, the total period of $27.7 \%, 22.2 \%$ and $13.5 \%$, respectively.Elective course is composed of professional courses and any electives, total of 42 and 12 , respectively accounted for $25.4 \%$ and $7.2 \%$ of the total credits, graduation period of 756 and 216 , respectively, of $28.3 \%$ and $8.1 \%$ of the total number of hours. Has the maximum number of credits and school is professional elective courses, the least is any elective courses.On the theory of curriculum, the compulsory courses and elective courses is reasonable collocation, for students not only master the professional knowledge must be laid a solid foundation, and takes into account the students personality and special skills, respect students' individual differences, according to their aptitude, give full play to each student's individual mental characteristics.

B. Nanjing sports college sports economic and management professional teaching effect analysis of undergraduate teaching

(1) The students' employment and professional internships with major related degree analysis

The table 4 shows that the vast majority of the students' employment and professional internships are its major with medium above the related degree, $18.9 \%$ of the students in the process of employment and professional practice and its closely related specialty, $36.7 \%$ of the students in the process of employment and professional practice is related to its more professional, 28.9\% of the students in the process of employment and professional practice is related to its specialty of medium, only $12.2 \%$ of the students in the process of employment and professional practice and is not related to your major, $3.3 \%$ of the students in the process of employment and professional practice is related to its not professional.This suggests that the sports economics and management graduates employment prospects look good. Now in urgent need of a large number of sports economy and sports industry management professionals, such as the state physical cultural administrative departments at all levels, sports management center, sports institutions, all kinds of enterprises, the commercial sports event organization department, all kinds of sports, a consulting firm, the large company of sports products, all kinds of fitness club, all kinds of sports broker companies, professional sports clubs, fitness clubs, sports intermediary companies, institutions of higher learning, and so on.

(2) Students in employment and professional practice, the application of the professional theory knowledge in the process of analysis

Will be to the professional theoretical knowledge they learned in class in terms of jobs and internships in the process of application, the table 5 shows that up to $43.3 \%$ of the students is only a general application, followed by $25.6 \%$ of the students application is less, application more students 
reached $21.1 \%$, only $7.8 \%$ of the students fully applied, no only $2.2 \%$ of students.A small number of students can make students in the practice teaching, effectively consolidate the imparting of knowledge theory, and the flexibility to use in practice. But there are more than half of all students in the process of practice for the application of professional theory knowledge for general, disconnection between theory teaching and practice teaching is a teaching process revealed a phenomenon.

\section{Conclusion}

(1)Nanjing sports college of economy and management professional teaching content and specific gravity, the proportion of practice lesson slightly weak.The arrangement of the classroom teaching of the compulsory courses and elective courses is relatively reasonable, accord with the actual students. The practice teaching content arrangement can in order to further improve and perfect the students' practical ability to lay a solid foundation。

(2)The vast majority of the students' employment and professional internships are its major with medium above the related degree, shows that the sports industry management graduates obtain employment prospect is good 。

(3)All students can realize the important role of practice teaching for their future employment.

However, there are more than half of all students in the process of practice the application of professional theory knowledge for the situation that primary and high school held a "very accord with" view to respondents who the most, most colleges and universities "meet" in opinion.

A. The analysis of the lack of funding

By different types of schools surveyed the table3, the "insufficient funds" issues of distribution, primary school, middle school, high school respondents in with the "very", most colleges and universities respondents to "meet" majority.

B. Analysis by the lack of space equipment

By table 4 respondents, different types of school for the lack of "equipment" issues of distribution, primary, secondary and tertiary colleges respondents are most by "meet", "high school most respondents with with the" very ".

C. Lack of further analysis of the way to learn

From table 5 different types of school respondents to a "lack of education way to learn" issues of distribution, primary school and high school respondents are as "very accord with" most, secondary and tertiary institutions most respondents are to "meet".

(1)On the whole, the current development of folk sports five before the main problems existing in the, in turn, are as follows: (1) the school lack of teachers; (2) lack of funding; (3)lack of stable sources of funds; (4)equipment; (5)lack of way for further study.

(2)In terms of comparison of different types of schools, each respondent on 10 issues, all have significant differences exist. (1) primary school in the organization training force consumed cost too much on the view of "in" the proportion of more than most; (2)secondary to "students' parents do not support", in the high proportion of "meet"; (3) high school in the lack of teachers "school", "insufficient funds" and so on, on the view of the above "meet" the highest proportion; (4) colleges and universities in the department in charge of the lack of policy support, etc, on the view of the highest percentage. 


\section{References}

[1] Zhong Jingwen. Introduction to folklore [M]. Shanghai: Shanghai Literature and Art Publishing House, 2009: 1-2.

[2] Bai Jinxiang. National folk sports [M]. Beijing: Higher Education Press, 2010: 3-4.

[3] Fu Yukun. Folk sports research [M]. Jinan: Shandong Education Press, 2012: 5.

[4] He Jinpeng, Zhang Zhicheng, Liu Kun. Analysis of the development of folk sports in China [J]. Guide, 2014 (2): 41-44.

[5] Huang Zhen. Northeast ethnic minority culture protection and inheritance thinking [J]. Heilongjiang ethnic clan

Journal, 2011 (3): 127-130. 